\title{
Microstructure and mechanical properties of extruded profiles made from pure magnesium powders
}

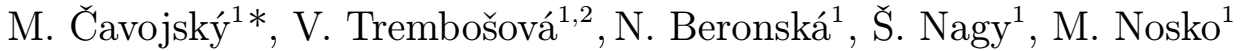 \\ ${ }^{1}$ Institute of Materials and Machine Mechanics, Slovak Academy of Sciences, \\ Dúbravská cesta 9, 84513 Bratislava, Slovak Republic \\ ${ }^{2}$ Faculty of Materials Science and Technology in Trnava, STU, Botanická 49, 91724 Trnava, Slovak Republic
}

Received 20 May 2019, received in revised form 17 July 2019, accepted 17 July 2019

\begin{abstract}
Magnesium-based biomaterials are good candidates as a new generation of biodegradable metals since magnesium $(\mathrm{Mg})$ can dissolve in body fluid. Therefore, implanted $\mathrm{Mg}$ can degrade during the healing process, and if the degradation rate is controlled no debris after completion of healing is expected. Besides its biocompatibility, inherent mechanical properties of $\mathrm{Mg}$ are very similar to those of human bone. This paper is focused on the possibility to prepare the pure $\mathrm{Mg}$ material from powders with further intention to use it as a biodegradable implant. Powders were consolidated via cold compaction to prepare the extrusion billets which were subsequently directly extruded to final profiles at a controlled temperature to avoid the formation of the thick oxide layer. The microstructure is revealed through SEM, SEM-EBSD, TEM, and HRTEM and mechanical properties are determined via a uniaxial tensile test. Results are compared with Mg ingot and WE43 alloy, which is commercially used for biodegradable (biocompatible) material.
\end{abstract} Ke y w or d s: magnesium, powder metallurgy, biocompatibility, microstructure, mechanical
properties

\section{Introduction}

Magnesium and its alloys are attractive engineering metals as they exhibit low density and high specific strength which makes them attractive in applications where their increased use can lead to significant saving cost and energy [1-4]. Moreover, they possess excellent biocompatibility and biodegradability, especially the magnesium with high-purity without the presence of any harmful elements. Therefore, they have the potential to be used in biomedical fields [5-7]. Several works have already described $\mathrm{Mg}$ or $\mathrm{Mg}$ alloys as a new class of degradable biomaterials for orthopedic implantations [8-10].

One of the main advantages of biodegradable implants is the elimination of follow-up surgery to remove the implant after the tissue has healed sufficiently [11, 12]. Although polymers are dominant in the current medical market, Mg-based [13, 14], Fe-based [15-17] and Zn-based alloys [18-20] have been proposed as better biodegradable materials for load-bearing applications due to their combination of strength and ductility over polymers. In general, mismatch of elastic moduli can lead to the implant carrying a more significant portion of the load and cause stress shielding of the bone [21]. This biomedical incompatibility can result in critical clinical issues, such as early implant loosening, damage to the healing process, skeletal thickening, and chronic inflammation [22]. The elastic modulus of pure magnesium and $\mathrm{Mg}$ alloys is $41-45 \mathrm{GPa}$ what is closest to natural bone (3$20 \mathrm{GPa})$ in comparison with steels $(\sim 211.4 \mathrm{GPa})$, titanium alloys $(\sim 193 \mathrm{GPa})$ or zinc alloys $(\sim 90 \mathrm{GPa})[11$, 20]. Moreover, magnesium implants have been proven to stimulate the formation of the new bone when they are implanted as bone fixtures [11]. With this knowledge, no further operations related to the removing implants are needed, and this advantage increases interest for further study of magnesium as a biomaterial.

Research in the suitability of magnesium and its

*Corresponding author: tel.: +421 2 32401024; e-mail address: miroslav.cavojsky@savba.sk 
alloys as implant materials has a long history [11] and is booming at present [23]. However, benefits of $\mathrm{Mg}$ associated with its non-toxicity and biodegradability do not match with its mechanical performance in spite of its modulus is close to natural bone. One of the limitations of pure magnesium concerning its use in medical implants is its low mechanical strength and poor ductility attributed to its hexagonal crystal structure [11]. To achieve a significant improvement in mechanical properties close to the value of commercially used WE43 alloy is needed.

Since scientific papers which are dealing with the extrusion of pure magnesium powders are relatively rare, and their properties or impact on the microstructure have not yet been described in detail, the aim of this work was, therefore, to prepare a suitable Mg-based material with improved mechanical properties without additives and powder surface treatment. This paper is focused on manufacturing the profiles through powder metallurgy (PM) route to evaluate microstructure and mechanical properties. The main goal is to analyze corrosion resistance in the future and to assume this material for use in biocompatible applications.

\section{Experimental}

In the present paper, $\mathrm{Mg}$ powder made by gas atomization in Ar atmosphere of $99.96 \%$ purity and mean particle size $\sim 15 \mu \mathrm{m}$ was used for the study. The chemical analysis was investigated by fluorescence ARL 9400 XP spectrometer with Rh cathode and $4 \mathrm{~kW}$ tube. The content of the impurities are $\mathrm{Zn}-0.076$ wt.\%, $\mathrm{Cu}-0.01$ wt.\%, Fe 0.079 wt. $\%$, and $\mathrm{Ni}-0.001$ wt. $\%$. The microstructure of the powders was studied using field emission scanning electron microscopy (FEG-SEM7600F, JEOL, Japan) equipped by energy dispersive spectrometry (EDS, Oxford Instruments X-Max $50 \mathrm{~mm}^{2}$ ) and electron back-scattered diffraction detector (EBSD, HKL Nordlys). Transmission electron microscopy (TEM, Jeol 1200EX and HR-STEM, FEI Titan Themis) was used to characterize the native $\mathrm{MgO}$ layer covering powders. Thin foils from powders were prepared through mixing powders with epoxy, curing the powder-epoxy mixture to form a bulk material, grinding the bulk to obtain a thin foil followed by ion milling with GATAN PIPS II machine. For the investigation of extruded samples, grinding, polishing, and etching was carried out.

To avoid undesirable grow of the native oxide layer on the Mg powders prior extrusion, differential thermal analysis (DTA) and thermal gravimetric analysis (TGA) were performed on-air to define extrusion temperature below the critical temperature. Vertical Linseis DTA/TGA combined with analyzer L81-II/1600 was used for this purpose. All experiments were carried out using the alumina crucible in the temperature range $25-640^{\circ} \mathrm{C}$, sample mass was $\sim 30 \mathrm{mg}$ with heating rate of $10^{\circ} \mathrm{C} \mathrm{min}^{-1}$ and cooling rate of $10^{\circ} \mathrm{C} \mathrm{min}^{-1}$. Green compacts of $\mathrm{Mg}$ powder, $30 \mathrm{~mm}$ in diameter and $60 \mathrm{~mm}$ in height were prepared by hot vacuum pressing (HVP) at $425 \mathrm{MPa}$ and $350^{\circ} \mathrm{C}$ for $1 \mathrm{~h}$. This process leads to overall degassing and helps to prevent subsequent oxidation during the extrusion process. Direct extrusion (DE) was performed at an average ram speed of $\sim 0.2 \mathrm{~mm} \mathrm{~s}^{-1}$ using an extrusion ratio of $R=16: 1$. Prior extrusion, green compacts were heated to $390{ }^{\circ} \mathrm{C}$ for $15 \mathrm{~min}$. The final extruded rods were $7.5 \mathrm{~mm}$ in diameter. Mechanical properties in tension were measured on tensile bars with a gauge of $\varnothing$ 5-30 $\mathrm{mm}$ using a ZWICK testing machine at a cross-ram speed of $6 \times 10^{-4} \mathrm{~min}^{-1}$ according to STN EN ISO 6892-1 standard. Measurement was performed parallel to the extrusion direction.

\section{Results and discussion}

\subsection{Microstructure}

Morphology and microstructure of $\mathrm{Mg}$ powders in cross-section with enlarged EDS elemental mapping are revealed in Figs. 1a,b. Spherical powder with $d 50=14.7 \mu \mathrm{m}$ (Fig. 1a) shows a smooth powder surface typical for the gas atomization. As seen in Fig. 1b, uniform distribution of the oxygen along the surface boundary is characteristic. The oxygen from the $\mathrm{MgO}$ crystalline envelope layer with a thickness of $\sim 100 \mathrm{~nm}$ was identified by TEM-SAED, as documented in Fig. 1c. The SAED ring pattern with crystallographic planes (200), (220), (222), etc., corresponds to a cubic $\mathrm{MgO}$ crystal structure according to PDF no. 00-004-0829.

$\mathrm{MgO}$ is a native oxide layer formed on the $\mathrm{Mg}$ surface as a result of the high affinity of $\mathrm{Mg}$ to oxygen immediately as the surface is exposed to air [24]. This native oxide layer should act as a barrier to dislocation motion during mechanical straining thus should improve mechanical properties of the profiles as in case of Al-based PM material made through direct extrusion as published by Balog et al. [25]. Moreover, based on literature [26, 27], such native envelope could act as a barrier to corrosion and improve biodegradable properties of $\mathrm{Mg}$ as in case of surface-treated powders WE43 with HF [28].

\subsection{Extrusion}

As mentioned in the experimental part, to avoid undesirable grow of the native oxide layer on $\mathrm{Mg}$ powders prior extrusion, DTA/TG analysis was performed. According to the results, we assumed that the 


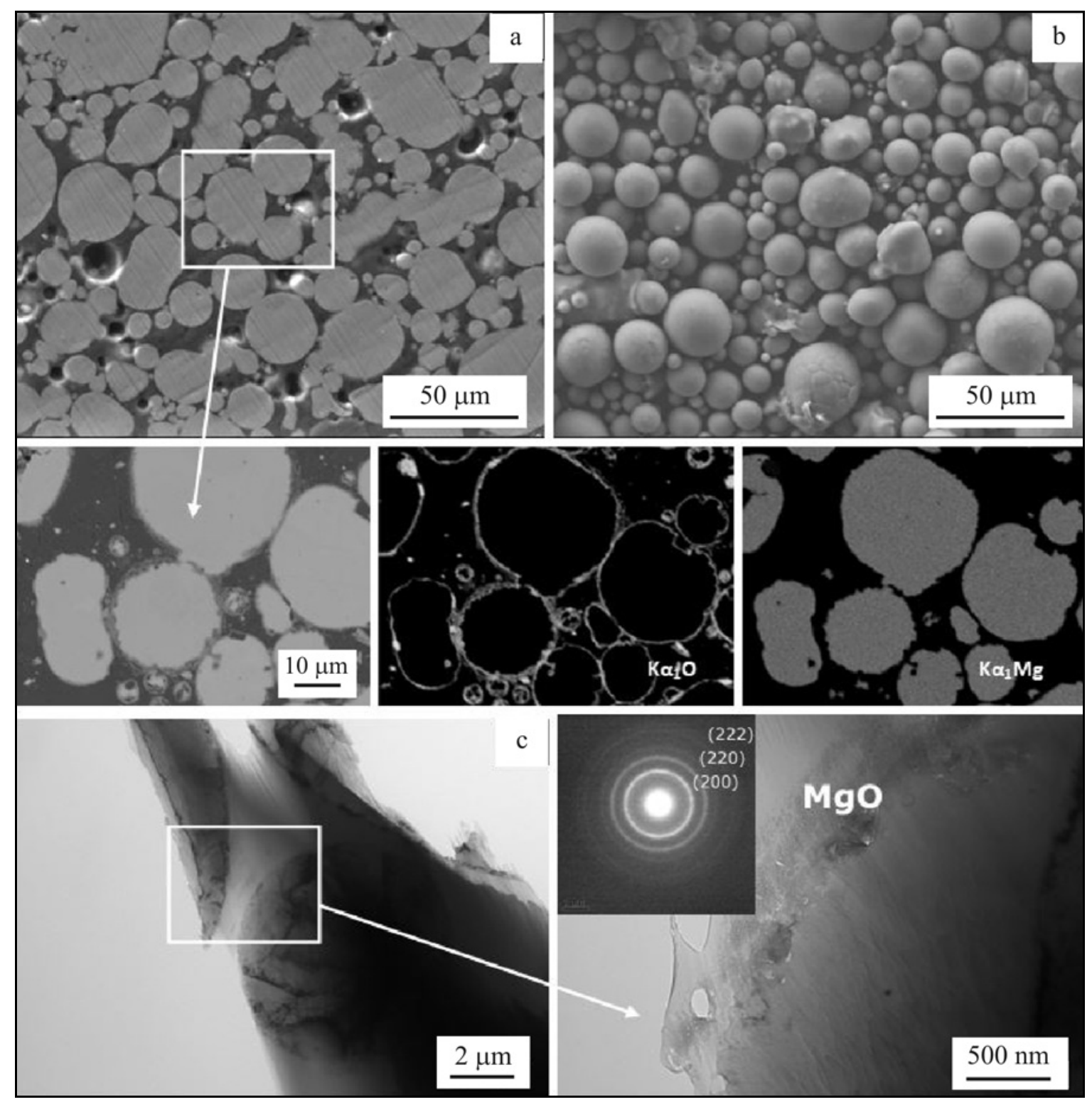

Fig. 1. SEM images representing Mg atomized powders: (a) particle size of Mg powders, (b) the cross-section of the Mg powder and EDS map of Mg powders, and (c) TEM images of $\mathrm{Mg}$ powders and detail from the oxide layer with SAED ring pattern indicating $\mathrm{MgO}$ crystals.

extrusion temperature $390^{\circ} \mathrm{C}$ would have no side effect on $\mathrm{Mg}$ powders as the oxidation took place at temperature range $\sim 547^{\circ} \mathrm{C}$. The results corresponded with Medved's et al. study [29] where they reported that $400^{\circ} \mathrm{C}$ could be considered as the minimum critical temperature for the oxidation of $\mathrm{Mg}$ alloys. Therefore, we assume that the air atmosphere under which extrusion would be done, should not affect the surface of the powders.

As seen in Fig. 2, the microstructure of the samples after extrusion shows strong texture characteristic with visible extrusion direction as confirmed by EBSD-IPF. EDS elemental maps reveal rather continuous $\mathrm{MgO}$ envelopes along the original powders with the presence of the $\mathrm{MgO}$ clusters aggregated during extrusion which looks on the Fig. $2 \mathrm{~b}$ as pits and voids within the microstructure. The thickness of the $\mathrm{MgO}$ layer ranged between approximately $150 \mathrm{~nm}$. Therefore, we have estimated the amount of $\mathrm{MgO}$ from EDS cross-sectional maps 0.06 vol.\%. XRD measurement did not show any sign of the MgO. TEM in hand with HRTEM image shown in Fig. 2c confirmed $\mathrm{MgO}$ nanocrystalline structure connected with the $\mathrm{Mg}$ structure on the interface. SAED pattern indicated $\mathrm{MgO}$ ring diffraction pattern with corresponding crystallographic planes as in case of $\mathrm{Mg}$ powders in Fig. 1. Above mentioned suggests that no transformation of the $\mathrm{MgO}$ or its thickness occur during the extrusion process. Therefore, it is proven that the selected temperature of $390{ }^{\circ} \mathrm{C}$ is suitable for the production of 


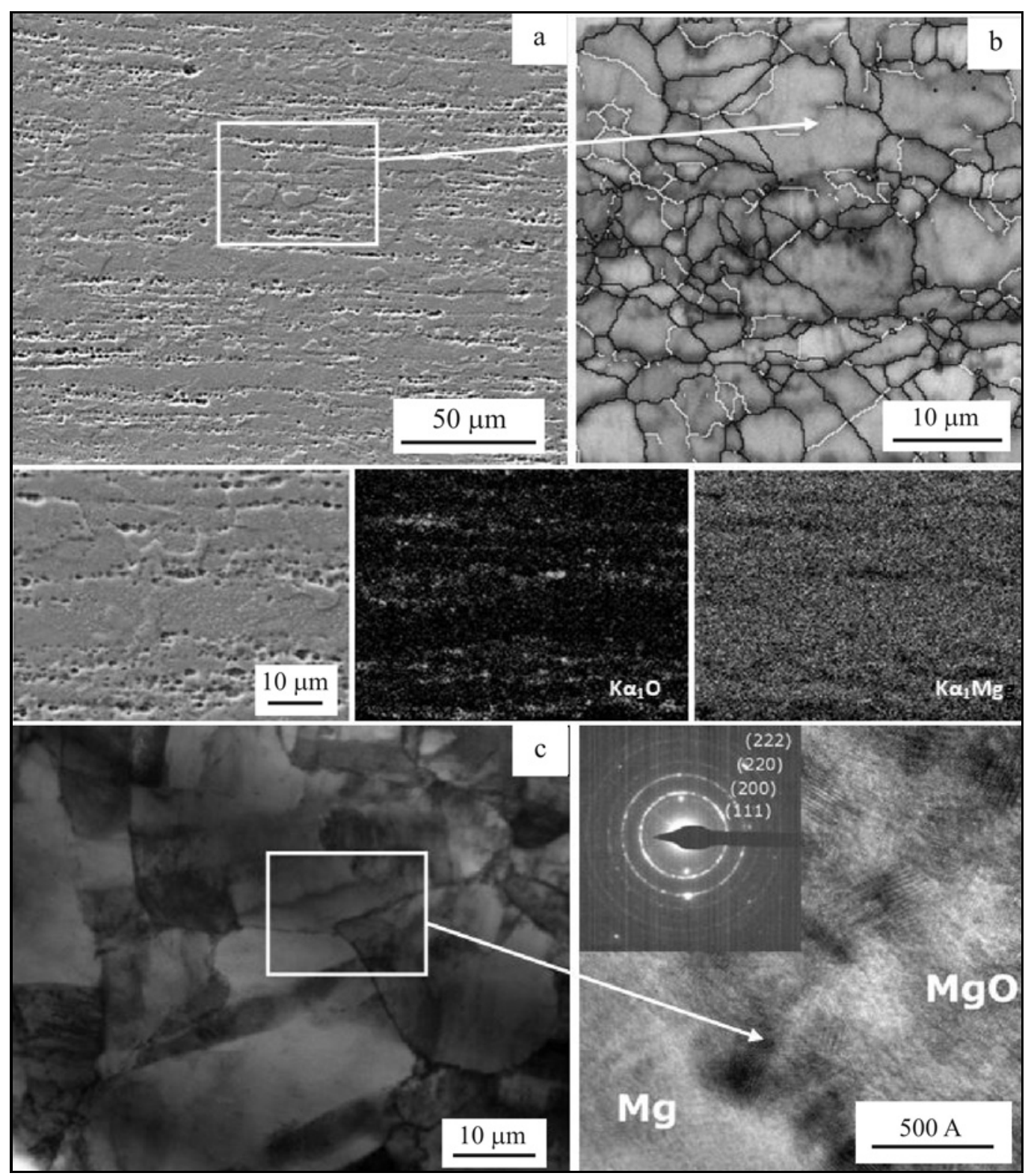

Fig. 2. SEM microscopy images of Mg powders prepared by extrusion: (a) Mg compact after extrusion, (b) EBSD and EDS map after extrusion, and (c)TEM analysis (left) of extruded material and the interface (right) of $\mathrm{Mg}$ and $\mathrm{MgO}$ with SAED ring pattern.

the Mg-based material through the powder metallurgy route.

\subsection{Mechanical properties}

The results from tensile tests of the extruded profile compared to WE43 PM (the results published by Kubásek in [30, 31]) are summarized in Fig. 3a. Figure 3 b shows representative tensile stress-strain curves for $\mathrm{Mg}$ materials. As illustrated, the stress-strain curve exhibits continuous strain hardening, which is typical for the extruded material from powders reported previously by Balog et al. [25] on Al powders. The typical value of ultimate tensile strength (UTS) of WE43 PM is $\sim 310 \mathrm{MPa}$ with uniform elongation of about $4 \%$. On the contrary, it can be seen that UTS of Mg PM is lower than WE43 PM by about $40 \mathrm{MPa}$. Differences in mechanical behavior are apparent in the values of the elongation for pure $\mathrm{Mg}$ powder material, which was almost $7 \%$. However, if we consider the use of $\mathrm{Mg} \mathrm{PM}$ as a biocompatible material, the values of $\mathrm{Mg}$ PM are comparable with those for WE43 PM, which is currently used for bioimplants [32].

It should be mentioned that the mechanical properties of WE43 alloy are mainly given by the amount of additive RE elements ( $\mathrm{Y}, \mathrm{Nd}$ ) that reinforce the material at the grain boundaries [30]. Moreover, the grain size of this material is also crucial since the size 

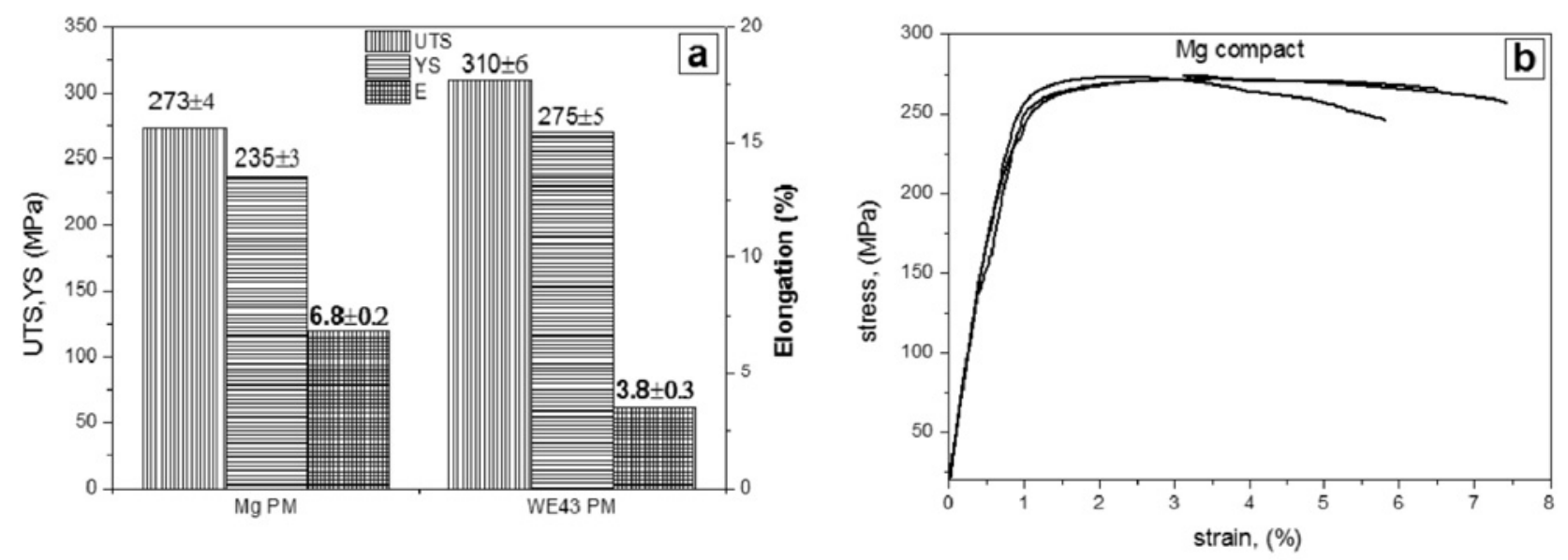

Fig 3. Mechanical properties (UTS, YS, and elongation): (a) the extruded Mg and WE43 alloys and (b) the representative tensile stress-strain curves of $\mathrm{Mg}$ materials.

is rather small $(100 \mu \mathrm{m})$ and according to Hall-Petch equation [33], the size of the grains strengthens the material due to grain boundary strengthening mechanism. Also, in the case of studied Mg PM, the mechanical properties can be related to grain size and grain boundaries strengthening, which is improved by the native oxide layer along with the original powders prior extrusion. Since this layer is compact after extrusion its increment to increase of the UTS is significant [25].

From the above mentioned, it could be concluded that the Mg PM material is a good candidate for the biocompatible and biodegradable material since the mechanical properties are significantly improved and approach WE43 values.

\section{Conclusions}

The possibility for production of the biocompatible material manufactured from $\mathrm{Mg}$ powders was thoroughly studied in terms of production, microstructure, and mechanical properties. It was shown that:

- Mg powders contain native oxide layer identified as $\mathrm{MgO}$, which is stable up to temperature $390^{\circ} \mathrm{C}$.

- It is possible to produce $\mathrm{Mg}$ profile from $\mathrm{Mg}$ powders through direct extrusion with continuous $\mathrm{MgO}$; however, parameters of the extrusion have to be thoroughly set.

- Mechanical properties of the Mg PM approach WE43 values.

- The material based on Mg PM could be considered as a biocompatible material, and corrosion resistance has to be studied.

\section{Acknowledgements}

This study was elaborated within the project VEGA
2/0098/19 "Study of the Use of Pure Magnesium Powders for the Preparation of Biodegradable Materials."

This work was performed during the implementation of the project Building-up Centre for advanced materials application of the Slovak Academy of Sciences, ITMS project code 313021T081 supported by Research \& Innovation Operational Programme funded by the ERDF.

\section{References}

[1] Mordike, B., Ebert, T.: Mater. Sci. Eng. A, 302, 2001, p. 37. doi:10.1016/S0921-5093(00)01351-4

[2] Cole, G.: In: IMA-Proceedings 2007. Saint Paul, Minnesota, International Magnesium Association 2007, p. 13.

[3] Easton, M., Beer, A., Barnett, M., Davies, C., Dunlop, G., Durandet, Y., Blacket, S., Hilditch, T., Beggs, P.: JOM, 60, 2008, p. 57. doi:10.1007/s11837-008-0150-8

[4] Pollock, T. M.: Science, 328, 2010, p. 986. doi:10.1126/science.118284

[5] Gu, X. N., Zhou, W. R., Zheng, Y. F., Liu, Y., Li, Y. X.: Mater. Lett., 64, 2010, p. 1871. doi:10.1016/j.matlet.2010.06.015

[6] Zhang, E. Yang, L.: Mater. Sci. Eng. A, 497, 2008, p. 111. doi:10.1016/i.msea.2008.06.019

[7] Kannan, M. B.: Mater. Lett., 79, 2012, p. 109. doi:10.1016/j.matlet.2012.02.050

[8] Yang, L., Huang, Y., Peng, Q., Feyerabend, F., Kainer, K. U., Willumeit, R., Hort, N.: Mater Sci. Eng. B, 179, 2011, p. 1827. doi:10.1016/j.mseb.2011.02.025

[9] Liu, D., Yang, D., Li, X., Hu, S.: J. Mater. Res. Technol., 8, 2018, p. 1538. doi:10.1016/j.jmrt.2018.08.003

[10] Radha, R., Sreekanth, D.: Journal of Magnesium and Alloys, 5, 2017, p. 286. doi:10.1016/j.jma.2017.08.003

[11] Staiger, M. P., Pietak, A. M., Huadmai, J., Dias, G.: Biomaterials, 27, 2006, p. 1728. doi:10.1016/j.biomaterials.2005.10.003

[12] Fare, S., Ge, Q. A., Vedani, M., Vimercati, G., Gastaldi, D., Migliavacca, F., Petrini, L., Trasatti, S.: Revista Matéria, 15, 2010, p. 103.

[13] Zhang, S., Zhang, X., Zhao, C., Li, J., Song, Y., Xie, C., Tao, H., Zhang, Y., He, Y., Jiang, Y., Bian, Y.: 
Acta Biomater., 6, 2010, p. 626.

doi:10.1016/i.actbio.2009.06.028

[14] Zhang, X. B., Yuan, G. Y., Niu, J. L., Fu, P. H., Ding, W. J.: J. Mech. Behav. Biomed. Mater., 9, 2012, p. 153. doi:10.1016/j.jmbbm.2012.02.002

[15] Li, Z. J., Gu, X. N., Lou, S. Q., Zheng, Y. F.: Biomaterials, 29, 2008, p. 1329. doi:10.1016/j.biomaterials.2007.12.021

[16] Peuster, M., Wohlsein, P., Brugmann, M., Ehlerding, M., Seidler, K., Fink, C., Brauer, H., Fischer, A., Hausdorf, G.: Heart, 86, 2001, p. 563. doi:10.1136/heart.86.5.563

[17] Feng, Q. M., Zhang, D. Y., Xin, C. H., Liu, X. D., Lin, W. J., Zhang, W. Q., Chen, S., Sun, K.: J. Mater. Sci. Mater. Med., 24, 2013, p. 713. doi:10.1007/s10856-012-4823-Z

[18] Schinhammer, M., Hanzi, A. C., Loffler, J. F., Uggowitzer, P. J: Acta Biomater., 6, 2010, p. 1705. doi:10.1016/j.actbio.2009.07.039

[19] Vojtech, D., Kubasek, J., Serak, J., Novak, P.: Acta Biomater., 7, 2011, p. 3515. doi:10.1016/j.actbio.2011.05.008

[20] Bowen, P. K., Drelich, J., Goldman, J.: Adv. Mater., 25, 2013, p. 2577. doi:10.1002/adma.201300226

[21] Seal, C. K., Vince, K., Hodgson, M. A.: IOP Conference Series: Materials Science and Engineering, 4, 2009, p. 12011. doi:10.1088/1757-899X/4/1/012011

[22] Salahshoor, M., Guo, Y. B.: Materials, 5, 2012, p. 135. doi:10.3390/ma5010135

[23] Virtanen, S.: Mater. Sci. Eng. B, 176, 2011, p. 1600. doi:10.3390/ma5010135
[24] Avedesian, M. M., Baker, H.: Magnesium and Magnesium Alloys. ASM Specialty Handbook. Materials Park, ASM International 1999.

doi:10.1016/i.mseb.2011.05.028

[25] Balog, M., Simancik, F., Walcher, M., Rajner, W., Poletti, C.: Mater. Sci. Eng. A, 529, 2011, p. 131. doi:10.1016/i.msea.2011.09.006

[26] Cui, L. Y., Gao, S. D., Li, P. P., Zeng, R. C., Zhang, F., Li, S. Q., Han, E. H.: Corros. Sci., 118, 2017, p. 84. doi:10.1016/j.corsci.2017.01.025

[27] Cui, L. Y., Liu, H. P., Zhang, W. L., Han, Z. Z., Deng, M. X., Zeng, R. C., Li, S. Q., Wang, Z. L.: J. Mater. Sci. Technol., 33, 2017, p. 1263. doi:10.1016/i.jmst.2017.10.010

[28] Dvorský, D., Kubásek, J., Vojtěch, D.: Mater. Lett., 227, 2018, p. 78. doi:10.1016/i.matlet.2018.05.052

[29] Medved, J., Mrvar, P., Vončina, M.: Oxid. Met., 71, 2009, p. 257. doi:10.1007/s11085-009-9141-6

[30] Kubásek, J., Dvorský, D., Cavojský, M., Vojtěch, D., Beronská, N., Fousová, M.: J. Mater. Sci. Technol., 33, 2017, p. 652. doi:10.1016/i.jmst.2016.09.019

[31] Dvorsky, D., Kubasek, J., Vojtech, D., Cavojsky, M.: Manuf. Technol., 16, 2016, p. 896. doi:10.1088/1757-899X/179/1/012018

[32] Li, N., Zheng, Y. F: J. Mater. Sci. Technol., 29, 2013, p. 489. doi:10.1016/j.jmst.2013.02.005

[33] Hall, E. O.: Proc. Phys. Soc. B, 64, 1951, p. 747. doi:10.1088/0370-1301/64/9/302 